\title{
A Microstructural Zone Model for the Morphology of Sol-Gel Coatings
}

\author{
T. SCHULER $\ddagger$, T. KRAJEWSKI, I. GROBELSEK AND M.A. AEGERTER* \\ Leibniz-Institut für Neue Materialien (INM), Im Stadtwald, Geb. 43, 66123 Saarbruecken/Germany \\ aegerter@inm-gmbh.de
}

\begin{abstract}
The thickness and the morphology of dip-coated single sol-gel layers is easily controlled by varying the sol compositions and the deposition parameters. A thorough study of the microstructure of transparent conducting $\mathrm{ZnO}$ :Al coatings deposited on fused silica substrates using X-ray diffraction, X-ray reflectometry and transmission electron microscopy cross-sections as well as of $\mathrm{In}_{2} \mathrm{O}_{3}: \mathrm{Sn}, \mathrm{SnO}_{2}: \mathrm{Sb}, \mathrm{ZnO}$ and $\mathrm{TiO}_{2}$ coatings reported in the literature shows that three basic morphologies can be observed: granular, layered and columnar. In multilayer systems they were found to depend essentially on the single layer thickness (SLT) and on the crystallite size determined from the data of thick films, a parameter called the "intrinsic crystallite size (ICS)". All the results so far analysed are in agreement with a 3-zone model when ICS is plotted against SLT or in a more refined version when $q=$ ICS/SLT is plotted against the homologous temperature $T_{\text {sintering }} / T_{\text {melting }}$. Comparison with the Movchan-Demchishin and Polley-Carter models proposed for PVD and CVD coatings, respectively, is presented.
\end{abstract}

Keywords: $\quad$ sol-gel coating, morphology, structure zone model, $\mathrm{ZnO}: \mathrm{Al}, \mathrm{ZnO}, \mathrm{SnO}_{2}: \mathrm{Sb}_{2} \mathrm{In}_{2} \mathrm{O}_{3}: \mathrm{Sn}, \mathrm{TiO}_{2}$

\section{Introduction}

Structure zone models (SZM) have been proposed as early as $1969[1,2]$ and refined by several authors [3, 4] to predict the influence of the working temperature and other deposition parameters on the morphology of thin metal and metal-oxide films produced by physical vapor deposition (PVD) techniques like evaporation [1] and sputtering [2] as well as by chemical vapor deposition (CVD) techniques like combustion CVD [5] and plasma enhanced CVD [6].

To our knowledge, an analogous model for films produced by sol-gel technique has never been proposed although it is known that the morphology of these coatings affects strongly their performance.

The paper presents first the results of a thorough experimental study of the microstructure of transparent conducting $\mathrm{ZnO}: \mathrm{Al}$ (AZO) coatings deposited on fused silica substrates $[7,8]$. Similar data obtained in our laboratory or reported by others for $\mathrm{In}_{2} \mathrm{O}_{3}: \mathrm{Sn}$ (ITO) [9, 10],

\footnotetext{
${ }^{\ddagger}$ Present address: Schott Glas, Hattenbergstraße 10, 55122 Mainz/ Germany.

*To whom all correspondence should be addressed.
}

$\mathrm{SnO}_{2}: \mathrm{Sb}$ (ATO) $[11,12], \mathrm{TiO}_{2}$ [13], $\mathrm{ZnO}(\mathrm{ZO})$ and AZO [13] have also been analysed. For the first time, a structural zone model for sol-gel coatings is proposed.

\section{Experimental}

The preparation of the different sols and the obtention of single and multilayer coatings described hereafter has been already reported before [7, 9-13].

For our own data (ATO, AZO) the thickness of sintered dip-coated layers was controlled by varying the sol concentration and the withdrawal speed from a few nanometers to about $200 \mathrm{~nm}$. It has been determined after chemical etching using a stylus profilometer (Tencor P10). Multilayer films have been obtained by repeating the same coating procedure. The parameter called "single layer thickness" (SLT) used to characterize single layers is the real physical thickness. For multilayer films, SLT was calculated as SLT $=d_{\text {stylus }} / N$ where $d_{\text {Stylus }}$ is the total thickness of the stacks and $N$ the number of layers deposited, although the first layer was usually found slightly thicker than the subsequent ones. Nevertheless, it describes the different systems with reasonable accuracy. 
The microstructure of the coatings has been determined using X-ray diffraction (Siemens D 500), X-ray reflectometry (X'Pert Philips or D 500 Siemens) and cross sectional transmission electron microscopy (CM 200 FEG, Philips). The crystallite sizes have been extracted from the X-ray data using the Scherrer equation [7]. They are average values that do not take into account possible variations through the coatings but they reflect however the influence of the different processing parameters (amount of dopants, parameters and methods of sintering, etc.). A parameter called "intrinsic crystallite size" (ICS) is defined as the crystallite size determined for films much thicker than the crystallite size. The values for coatings taken from the literature are those from X-ray data or alternatively were estimated from the TEM images. For those presenting a columnar structure without X-ray data, the base diameter of the columns was taken as ICS.

In order to compare the different data sets, the resulting structures are described by the ratio $q=$ ICS/SLT.

\section{Results and Discussion}

For AZO coatings, four different morphologies have been observed depending on the $q$ value.

A granular structure was found for all single and multilayer films when SLT $\gg$ ICS $(q \ll 1)$. A typical example is shown for a single AZO layer by the TEM cross-section in Fig. 1 (top). The coating was obtained using a concentrated sol $(0.47 \mathrm{~mol} / \mathrm{l})$ doped with 0.6 at\% Al, a withdrawal speed of $5 \mathrm{~mm} / \mathrm{s}$, a 10 min drying at $110^{\circ} \mathrm{C}$ and a subsequent firing in air for $30 \mathrm{~min}$ at $600^{\circ} \mathrm{C}$. The single layer thickness SLT is $156 \mathrm{~nm}$, the average crystallite size calculated from the (002) reflection is $41 \mathrm{~nm}$ resulting in $q=0.28$.

A layered structure was observed when the SLT value ranges between $1 \times \mathrm{ICS}<\mathrm{SLT}<2.4 \times \mathrm{ICS}$ i.e. for $0.42<q<1$. An example is shown in Fig. 1 (middle) for a 5-layer $\mathrm{ZnO}: \mathrm{Al}$ coating made with a medium concentrated sol $(0.2 \mathrm{~mol} / \mathrm{l})$ containing 5 at $\%$ Al. Each layer was withdrawn at $1 \mathrm{~mm} / \mathrm{s}$ and fired for $3 \mathrm{~min}$ at $550^{\circ} \mathrm{C}$. The total thickness of the stack is 91 $\mathrm{nm}$, the SLT is $18.2 \mathrm{~nm}$ and the corresponding ICS is $15 \mathrm{~nm}$ resulting in $q=0.82$.

A columnar structure was observed in multilayer coatings when SLT $<$ ICS, i.e. when $q>1$. The crystallite sizes are larger or in the range of the thickness of each single layer. Such a morphology is shown in Fig. 1 (bottom) for a 20-layer $\mathrm{ZnO}$ :Al coating. The layers have been deposited using a low concentrated
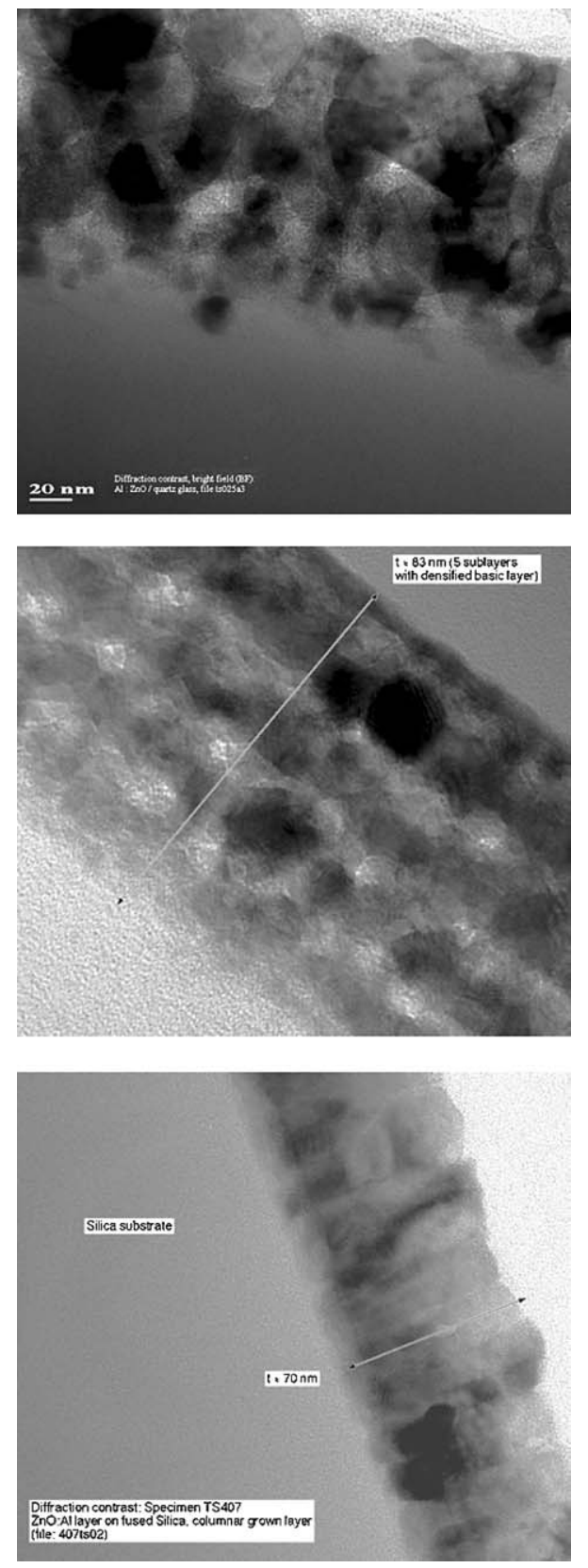

Figure 1. TEM-cross sections of AZO layers dip-coated on fused silica substrates. Top: granular structure of a single layer. Sol: $0.47 \mathrm{~mol} / 1 \mathrm{sol}$ with 0.6 at\% Al content; withdrawal speed: $5 \mathrm{~mm} / \mathrm{s}$, drying: $10 \mathrm{~min}$ at $110^{\circ} \mathrm{C}$, firing: $30 \mathrm{~min}$ at $600^{\circ} \mathrm{C}$. The total thickness is $156 \mathrm{~nm}$ and the crystallite size is $41 \mathrm{~nm} . q=0.28$. Middle: Layered structure of 5 layers. Sol: $0.2 \mathrm{~mol} / \mathrm{l}-\mathrm{sol}$ with 5 at\% $\mathrm{Al}$; withdrawal speed: $1 \mathrm{~mm} / \mathrm{s}$; each layer was fired for $3 \mathrm{~min}$ at $550^{\circ} \mathrm{C}$. The total thickness is $91 \mathrm{~nm}$ and the ICS is $15 \mathrm{~nm} . q=0.82$. Bottom: Columnar structure of 20 layers. Sol: $0.05 \mathrm{~mol} / 1$ with 0.6 at $\% \mathrm{Al}$; withdrawal speed: $1 \mathrm{~mm} / \mathrm{s}$; each layer was fired for $3 \mathrm{~min}$ at $450^{\circ} \mathrm{C}$. The total thickness is $72 \mathrm{~nm}$, the crystallite size is $26 \mathrm{~nm}$, ICS is $15.1 \mathrm{~nm} . q=4.2$. 


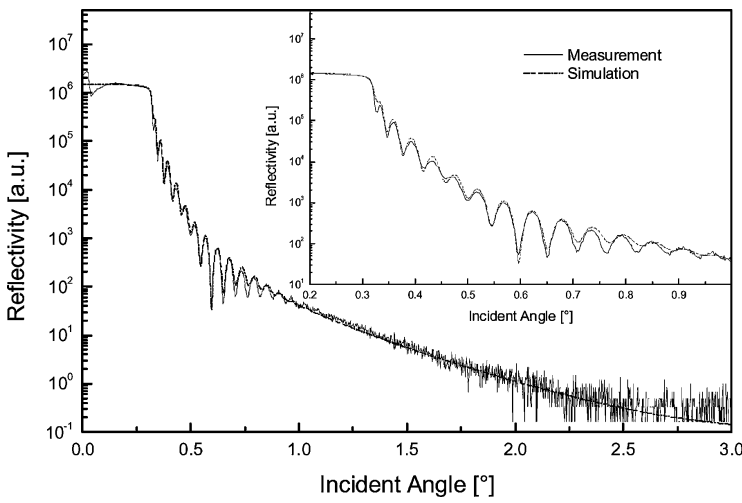

Figure 2. X-ray reflectometry of the structure shown in Fig. 1 bottom and best fit using a 3-layer model (see text).

sol $(0.05 \mathrm{~mol} / \mathrm{l})$ doped with 0.6 at $\%$ aluminium at a withdrawal speed of $1 \mathrm{~mm} / \mathrm{s}$ and fired for $3 \mathrm{~min}$ at $450^{\circ} \mathrm{C}$. The total thickness of the stack is $72 \mathrm{~nm}$, SLT is $3.6 \mathrm{~nm}$ and the crystallite size (002 reflection) is $26 \mathrm{~nm}$. The corresponding ICS is $15.1 \mathrm{~nm}$ resulting in $q=4.2$. The image shows characteristic dendritic shaped grains. One of the AZO coatings presented a highly dense columnar-granular structure made of $10 \mathrm{~nm}$ grains arranged in columns (not shown here).

Additional information such as the density profile across the layers was obtained by fitting the X-ray reflectometry curves [8]. An example is shown in Fig. 2 for the coating having the columnar structure (Fig. 1 bottom). The best fit was obtained using a 3-layer model (glass/ \#1/ \#2/ \#3/ air) where the inside layer (\#2) has a thickness of $60.9 \mathrm{~nm}$ and a high density $(\rho=$ $5.12 \mathrm{~g} \mathrm{~cm}^{-3}$, i.e. $90.1 \%$ of the pure $\mathrm{ZnO}$ theoretical density $\left.\rho_{\text {th }}\right)$, whereas the glass interface layer (\#1) is very thin $(5.5 \mathrm{~nm})$ with a low density $\rho=3.54 \mathrm{~g} \mathrm{~cm}^{-3}$ (62\% of $\rho_{\text {th }}$ ) and the coating/air interface layer (\#3) is also very thin $(3.1 \mathrm{~nm})$ with a density $\rho=3.03 \mathrm{~g} \mathrm{~cm}^{-3}$ ( $53.3 \%$ of $\rho_{\text {th }}$ ). The granular structures can be described by a 1 to 3 low density layers of about 50 to $70 \%$ of $\rho_{\text {th }}$. The best fits of the layered structures were obtained by describing each layer as a 2-layer high/low density stack (twice the number of layers effectively deposited [8]) with typical densities of 5.0 to 5.3 and 3.0 to $3.1 \mathrm{~g} \mathrm{~cm}^{-3}$, respectively.

The values of ICS and SLT of all AZO coatings as well as those obtained at INM and in other groups for ATO, AZO, ITO, ZO and $\mathrm{TiO}_{2}$ coatings produced with different preparation and deposition parameters are plotted in Fig. 3. According to this diagram, all columnar structures (square symbols), layered structures (diamonds), granular structures (circles) and the columnar-granular structure (crossed square) are lying in well defined regions.

The data are better displayed in Fig. 4 in terms of a structure zone model (SZM) where the ratio $q$ is plotted against the homologous temperature

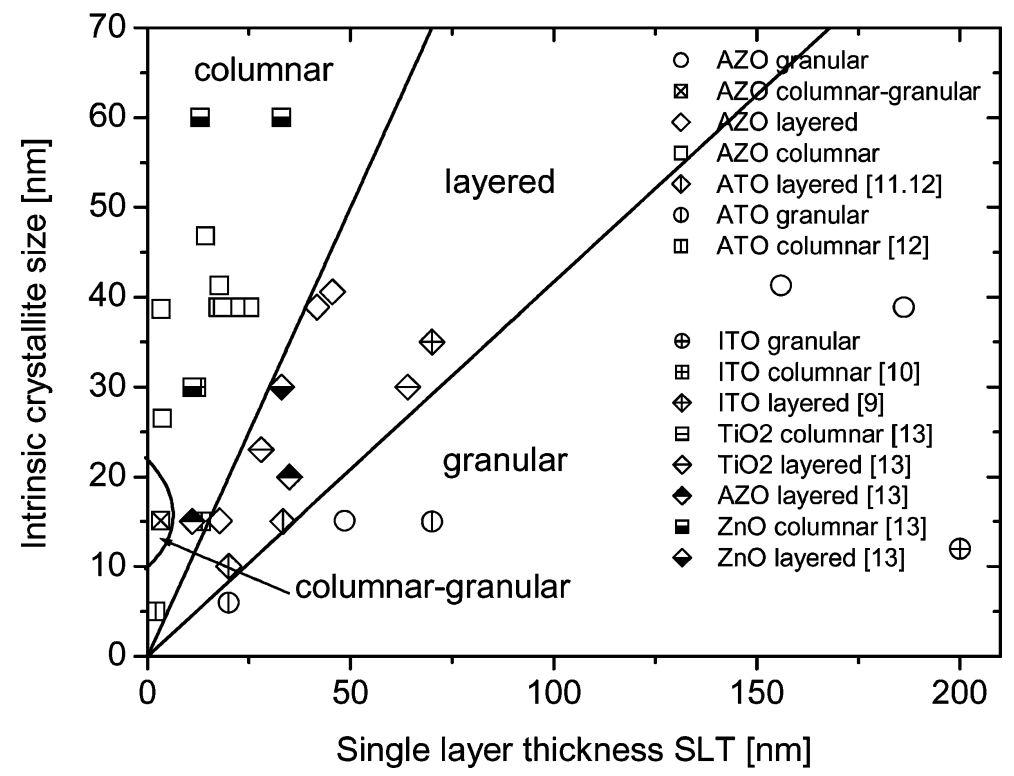

Figure 3. "Intrinsic crystallite size" vs. "single layer thickness" of the structures observed for sol-gel AZO films (this study) and from the literature for $\mathrm{AZO}$, ITO, ATO, $\mathrm{ZO}$ and $\mathrm{TiO}_{2}$ films showing 4 distinct regions. 


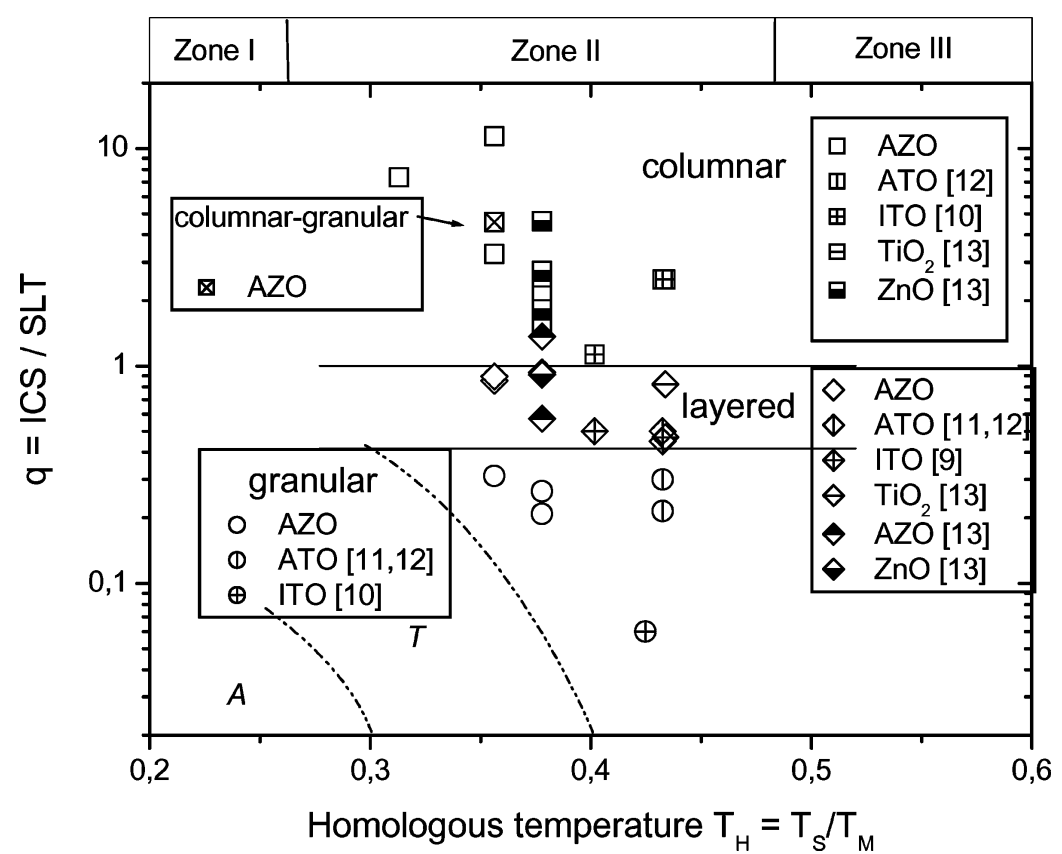

Figure 4. Structure parameter $q$ of all investigated systems vs. the homologous temperature $T_{H}=T_{\text {sintering }} / T_{\text {melting }}$. These temperatures are abbreviated $T_{S}$ and $T_{M}$ respectively. A and $T$ indicate possible sol-gel amorphous and transition regions as observed in $\mathrm{ZnO}$ coatings made by combustion CVD process [5] (see text).

$T_{\mathrm{H}}=T_{\text {sintering }} / T_{\text {melting }}$ where $T_{\text {sintering }}$ is the temperature at which the coatings have been finally treated and $T_{\text {melting }}$ is the melting temperature of the materials. All data lie within the zone II $\left(0.3<T_{\mathrm{H}}<0.5\right)$ of the Movchan and Demchishin model, a region characteristic for PVD films with columnar grains separated by distinct intercrystalline boundaries [1]. Zone I of this model consisting of tapered crystals with domed tops separated by voided boundaries and zone III characteristic of equiaxed grains with a bright surface are not observed in sol-gel coatings. The sol-gel zone boundaries depend on the $q$ values. The columnar structure region is observed for sol-gel coatings made of thin single layers and is located at the top of the diagram where $q>1$. In PVD and CVD processing, the deposited layers grow continuously at a low rate. If a structure parameter $q$ had to be defined for such processes, its value would be high $(q \gg 1)$ as it would involve the ratio of an intrinsic crystallite size, ICS, to an instantaneous very small thickness, SLT. Our findings are therefore in agreement with those observed for coatings made by these processes. The observation of layered and granular structures in sol-gel processing for smaller $q$ values is particular interesting as these structures are not observed in PVD or CVD processing because of the too high value of $q$. The difference between sol-gel and PVD or CVD coatings is therefore quite understandable.

Recently Polley and Carter [5] showed that for pure $\mathrm{ZnO}$ films produced by a combustion CVD process, an amorphous zone, corresponding approximately to the region labelled $\mathrm{A}$ in Fig. 4, could be observed for $T_{\mathrm{H}}<0.3$ as well as a transition zone, extending towards the zone II and corresponding approximately to the region labelled $T$ in Fig. 4. The zone III could not be reached because of the sublimation onset at $T_{\mathrm{H}}=0.51$. Both boundaries were found to move to lower $T_{\mathrm{H}}$ values when the concentration of the solution used in this combustion CVD process decreased. In our model a decrease in solution concentration leads to a decrease of the SLT value and consequently to an increase of the value of the structure parameter $q$. The dotted lines shown in Fig. 4 indicate a possible trend for sol-gel layers. It is worth to remember that layered and granular structures have not been observed by these authors.

A structure zone model picture for sol-gel films based on all the data analysed so far is proposed in Fig. 5. The regions where the three main structures (columnar, layered and granular) are shown in a $q$ vs. $T_{\mathrm{H}}$ diagram. 


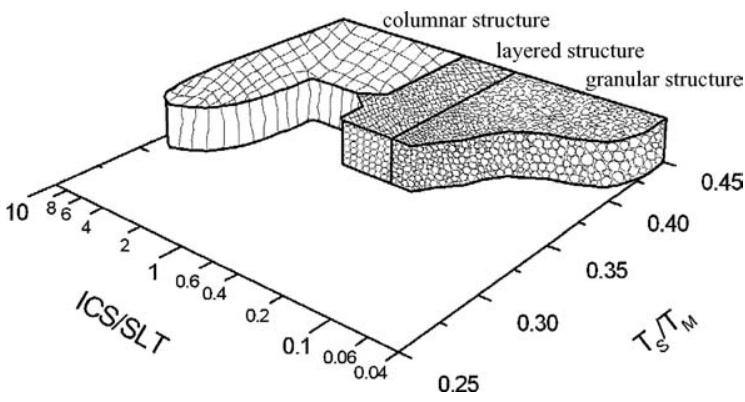

Figure 5. Proposed structure zone model for sol-gel coatings studied so far showing in a $q$ vs. $T_{\mathrm{H}}$ plot the regions where the three main sol-gel structures (columnar, layered and granular) have been found.

\section{Conclusion}

Sol-gel coatings exhibit essentially granular, layered or columnar structures that have been observed at INM and in other laboratories in single and multilayer AZO, ATO, ITO, ZO and $\mathrm{TiO}_{2}$ coatings. Their formation depends on several processing parameters which have been identified. Based on these observations a structural three zone model is proposed to predict the microstructure of the coatings in terms of the ratio of the intrinsic crystallite size, the single layer thickness and the homologous temperature defined as the ratio of the sintering temperature to the melting temperature.

\section{Acknowledgment}

The authors thank the State of Saarland and the Federal Ministry for Research and Education (Germany) for financial support.

\section{References}

1. B.A. Movchan and A.V. Demchishin, Physics of Metals and Metallography 28, 93 (1969).

2. J.A. Thornton, Ann. Rev. Mater. Sci. 7, 239 (1977).

3. R.A. Messier, P. Giri, and R.A. Roy, J. Vac. Sci. Technol. A 2(2), 500 (1984).

4. P.-J. Kelly and R.D. Arnell, J. Vac. Sci. Technol. A 16(5), 2858 (1998).

5. T.A. Polley and W.B. Carter, Thin Solid Films 384, 177 (2001).

6. B. Dumay, E. Finot, M. Theobald, O. Legaie, J. Durand, P. Baclet, and J.P. Goudonnet, J. Appl. Phys. 92(11), 6572 (2002).

7. T. Schuler and M.A. Aegerter, Thin Solid Films 351, 125 (1999).

8. T. Schuler, PhD Thesis, Verdichtung und Kristallisation von Transparenten Leitfaehigen Oxydischen Sol-Gel-Schichten am Beispiel des Zinkoxids, INM and University of Saarland, Saarbrücken, Germany, 2003.

9. Y. Takahashi, H. Hayashi, and Y. Ohya, Mat. Res. Soc. Symp., Proc. 271, 401 (1962).

10. Y. Takahashi, S. Okada, R. Bel Hadj Tahar, K. Nakano, T. Ban, and Y. Ohya, J. Non-Cryst. Solids 218, 129 (1997).

11. M.A. Aegerter, A. Reich, D. Ganz, G. Gasparro, and J. Pütz, J. Non-Cryst. Solids 218, 123 (1997).

12. C. Goebbert, G. Gasparro, T. Schuler, T. Krajewski, and M.A. Aegerter, J. Sol-Gel Sci. Technol. 19, 435 (2000).

13. Y. Ohya, H. Saiki, T. Tanaka, and Y. Takahashi, J. Am. Ceram. Soc. 79(4), 825 (1996). 